\title{
The Influence of Family Support on Self Efficacy of Chronic Kidney Disease
}

\author{
Nur Isnaini ${ }^{1 *}$ Risang Sukma ${ }^{2}$ Happy Dwi Aprilina ${ }^{3}$ \\ ${ }^{1}$ Lecturer in Nursing Department, Faculty of Health Sciences, Universitas Muhammadiyah Purwokerto* \\ ${ }^{2}$ Nursing Students, Faculty of Health Sciences Universitas Muhammadiyah Purwokerto \\ ${ }^{3}$ Lecturer in Nursing Department, Faculty of Health Sciences, Universitas Muhammadiyah Purwokerto \\ *Corresponding author. Email: nurisnaini@ump.ac.id
}

\begin{abstract}
Introduction: Patients with chronic kidney disease must be able to undergo hemodialysis therapy, medication, fluid restriction, and diet. Self-efficacy of patients is needed so that all therapies can work well. Besides, family support is no less important so that patients are confident and able to undergo self-management. Method: This research is a quantitative study using, a cross-sectional approach. The research sample was 48 respondents. The research instrument used a family support questionnaire and self-efficacy questionnaire. Moreover, the questionnaires had been tested for validity and reliability. The data were then analyzed using spss 16 software of Pearson correlation test. Results: Most respondents, as many as 18 patients $(37.5 \%)$ were between $46-55$ years old, female were 28 patients $(28.3 \%)$, married were 44 patients $(91.7 \%)$, had primary school education were 21 patients (43.8\%), and most of the respondents did not work, as many as 33 patients (68.8\%). The bivariate analysis results between family support and self-efficacy showed a $p=0.00$ with a strength of 0.783 relationships. Conclusion: There is a strong relationship between family supports for self-efficacy, so that patients with chronic kidney disease need family support.
\end{abstract}

\section{Keywords: Family Support, Self-Efficacy, Chronic Kidney Disease}

\section{INTRODUCTION}

Chronic kidney disease (CKD) is a public health problem around the world, including Indonesia. The prevalence of incidence of CKD worldwide is $13.4 \%$ (11.7$15.1 \%$ ). Patients with end-stage renal disease (ESRD) are in dire need of renal replacement therapy with an estimated case rate of between 4.902 and 7.083 million. Kidney disease greatly affects the cardiovascular system disorders and the incidence of ESRD. CKD directly affects global morbidity and mortality rates around the world. The increase in the incidence of global disease is due to diabetes mellitus, obesity, hypertension, and aging. A strategy is urgently needed to reduce the cardiovascular risk of CKD [1].

Patients with Chronic Kidney Disease (CKD) are required to undergo a series of medications and treatments that are diverse and make it difficult for patients to apply them. [2]. Management of chronic kidney disease patient care includes dialysis process, administration of drugs, regulation of fluid restrictions, and dietary regulation[3]. Comprehensive care management for CKD patients in the form of dialysis, medication administration, fluid management and dietary management is essential for the success of therapy and prevention of CKD complications. However, the majority of patients in this study indicated that CKD patients deviated more from the recommended dialysis management, medication administration, and fluid restriction[4]. The problem of non-compliance with CKD care becomes a challenge for the health team to find a solution[5].
Integrated management of chronic kidney disease (CKD) changes a person's life significantly because patients have to undergo dialysis, be given medication, and limited diet and fluids. Therefore, it is the duty of nurses and the team handling patients to provide appropriate interventions in terms of motivating so that patients increase their confidence. Motivation and support from closest people and family can be used to change patient behavior as recommended in the integrated management of CKD patients[6]. The existence of a family can provide significant support to patients and reduce the level of depression in patients with CKD [7]. Research in Korea states that the economic status and family characteristics of patients affect the level of family support received by patients, and this family support affects the patient's positive psychology and positive patient behavior This study provides useful information that there is a need to develop a family support intervention program for haemodialysis patients [8].

Self-efficacy theory explains how self-efficacy develops and is changed, as well as how self-efficacy affects behavior change, performance achievement, and personal well-being [9]. The definition of self-efficacy is a belief in one's own ability to take care of the motivation, cognitive abilities, and actions needed to meet conditions and situations. The concept of self-efficacy was born from changes in cognitive thinking, social experiences, heard information, or physical experiences carried out by patients [10]. Self-efficacy will greatly assist patient selfmanagement in carrying out therapy, diet management, and lifestyle changes [11]. This study aims to determine the 
effect of family support on the self-efficacy of CKD patients undergoing hemodialysis therapy at RSI Purwokerto.

\section{MATERIALS AND METHODS}

\subsection{Participants}

The population in this study were all CKD patients who were undergoing HD therapy at RSI Purwokerto, Central Java Indonesia, totaling 57 people. The criteria for the research sample that had been determined were CKD patients with hemodialysis therapy twice, age $\geq 18$ years and patients willing to become respondents. The exclusion criteria defined were patients with aa worsening condition. From these criteria, it was obtained 48 respondents.

\subsection{Measurements}

Measurement of research variables using instruments that support family consisting of 9 statements and selfefficacy instruments consisting of 11 statements. Previously, the instrument validity test had been carried out on 20 respondents from other hospitals, namely the hemodialysis unit of Goeteng Tarunadibrata Purbalingga Hospital, Central Java, Indonesia. The results of the reliability test carried out from the family support variable were 0.713 (high reliability coefficient), the efficacy variable obtained a Cronbach Alpha $(\alpha)$ value of 0.750 (high reliability coefficient), and the fluid intake variable obtained a Cronbach Alpha value $(\alpha)$ of 0.825 (highreliability coefficient). Based on the obtained values, it can be said that the three questionnaires are reliable and can be used for the research.

\subsection{Statistical Analysis}

Measurement of instrument's validity used the Pearson product moment and measurement of the reliability test used the Cronbach Alpha method. Univariate data analysis used frequency and percentage distributions, while bivariate analysis between variables of family support and self-efficacy used the Pearson Correlation test. Data analysis in this study used SPSS 16.

\section{RESULTS}

Table 3.1 Description of Respondent Characteristics based on age, gender, marital status, education, and employment status.

\begin{tabular}{|c|c|c|c|}
\hline \multicolumn{2}{|c|}{ Characteristics } & $\begin{array}{l}\text { Frequency } \\
(n=48)\end{array}$ & $\begin{array}{l}\text { Percentage } \\
(\%)\end{array}$ \\
\hline \multicolumn{4}{|c|}{ Age: } \\
\hline- & $17-25$ & 1 & 2,1 \\
\hline- & $26-35$ & 2 & 4,2 \\
\hline- & $36-45$ & 13 & 27,1 \\
\hline- & $46-55$ & 18 & 37,5 \\
\hline- & $56-65$ & 8 & 16,7 \\
\hline- & $>65$ & 6 & 12,5 \\
\hline \multicolumn{4}{|c|}{ Gender: } \\
\hline- & Male & 20 & 41,7 \\
\hline- & Female & 28 & 58,3 \\
\hline \multicolumn{4}{|c|}{ Marital status: } \\
\hline
\end{tabular}

\begin{tabular}{lcc}
\hline Characteristics & $\begin{array}{l}\text { Frequency } \\
(\mathrm{n}=48)\end{array}$ & $\begin{array}{c}\text { Percentage } \\
(\%)\end{array}$ \\
\hline - Widow & 2 & 4,2 \\
- Married & 44 & 91,7 \\
\hline Education: & 5 & \\
College & 21 & 10,4 \\
Primary school & 12 & 43.8 \\
Senior High School & 10 & 25,0 \\
Junior high school & & 20,8 \\
\hline Job status: & 15 & \\
Work & 33 & 31,2 \\
Unemployment & & 48 \\
\hline Total & & 68,8 \\
\hline
\end{tabular}

Based on table 3.1, it is known that the distribution of the characteristics of the respondents with chronic kidney failure in the hemodialysis room of RSI Purwokerto based on the age level is mostly at the age of 46-55 years as many as 18 patients $(37.5 \%)$, then the vulnerable aged $36-45$ years are 13 patients $(27,1 \%)$, aged 56-65 years were 8 patients $(16.7 \%), 6$ patients aged 65 years and over (12.5\%), 2 patients aged $26-35$ years $(4.2 \%)$ 17-25 years old as many as 1 patient $(2.1 \%)$.

The most frequent distribution based on gender was female respondents with as many as 28 patients $(28.3 \%)$ and male respondents as many as 20 patients $(41.7 \%)$. Characteristics of respondents based on marital status, the most frequent distribution of marital status was 44 patients $(91.7 \%)$ of married status, then 4 patients $(4.2 \%)$ with widow status and 4 patients $(4,4) .2 \%)$. Furthermore, based on the educational status, the highest number of respondents was elementary school education with a frequency of 21 patients (43.8\%), then junior high school education was 10 patients (20.8\%), high school education was 12 patients $(25.0 \%)$ and university level education was as much as 5 patients (10.4\%).

In addition, the frequency distribution of characteristics based on work status was mostly dominated by respondents who did not work as many as 33 patients $(68.8 \%)$ and patients who worked as many as 15 patients $(31.2 \%)$.

Tabel 3.2. Frequency Distribution of Family Support Level in Chronic Kidney Failure Patients

\begin{tabular}{lcc}
\hline Level of family support & $\begin{array}{l}\text { Frequency } \\
(\mathrm{n}=48)\end{array}$ & $(\%)$ \\
\hline Sufficiently support & 24 & 50,0 \\
extremely support & 16 & 33,3 \\
Do not support & 8 & 16,7 \\
\hline \multicolumn{1}{c}{ Total } & 48 & 100 \\
\hline
\end{tabular}

Based on table 3.2, it is known that the family sufficiently supported patients with chronic kidney failure who underwent HD at RSI Purwokerto as many as 24 patients $(50.0 \%)$. Patients with a very supportive family support level were 16 patients $(33.3 \%)$, and 8 patients with the level of family support did not support (16.7\%). 
Table 3.3. Frequency Distribution of Self-Efficacy Levels in Chronic Kidney Failure Patients

\begin{tabular}{lcc}
\hline Self-efficacy level & $\begin{array}{l}\text { Frequency } \\
(\mathrm{n}=48)\end{array}$ & $(\%)$ \\
\hline Pretty sure & 27 & 56,2 \\
Very confident & 14 & 29,2 \\
Not sure & 7 & 14,6 \\
\hline Total & 48 & 100 \\
\hline
\end{tabular}

Based on table 3.3, it is known that chronic renal failure patients undergoing HD therapy at RSI Purwokerto who have self-efficacy levels are quite confident with the highest frequency, namely 27 patients $(56.2 \%)$, then the self-efficacy level is very confident as many as 14 patients $(29.2 \%)$. ). The level of self-efficacy was unsure as many as 7 patients $(14.6 \%)$.

Table 3.4. The Effect of Family Support on Self-Efficacy of Patients with Chronic Kidney Failure in the Hemodialysis Room at RSI Purwokerto 2020

\begin{tabular}{lccc}
\hline \multicolumn{1}{c}{ Variable } & $\mathrm{N}$ & $\begin{array}{c}\text { Pearson } \\
\text { Correlation } \mathrm{r} \\
\text { value }\end{array}$ & -value \\
\hline $\begin{array}{l}\text { Family } \\
\text { Support and }\end{array}$ & 48 & $.783^{* *}$ & 0.000 \\
$\begin{array}{l}\text { Self } \\
\text { Efficacy. }\end{array}$ & & & \\
\hline
\end{tabular}

Based on table 4.4, it is known that the Pearson product moment correlation coefficient is .783**. This result means that $\mathrm{R}$ count of ( 0.783$)$ obtains the large correlation or relationship between family support variables and selfefficacy> $r$ table $(0.285)$, which means that the relationship between family support and self-efficacy shows a strong relationship and a positive pattern, meaning that the increasing family support, the more it increases to self-efficacy of respondents.

The application of a family-centered empowerment model with the participation of family members will improve self-care and encourage a lifestyle in hemodialysis patients [12]. Research conducted by [13] The results showed that patients who had family support had a significant correlation with the level of attention to fluid intake compared to patients who had less family support. This study did not link family support with comments on dietary restrictions. Family support here cannot be obtained because of the patient's level of physical disruption.

CKD patients with low family support showed a lower life expectancy and a higher depression score than patients who received full family support, seen from the depression level and life expectancy scores. This study concluded that anxiety, depression level, and social support from family can increase the life expectancy of CKD patients. Multidisciplinary care, including psychiatric consultation, is also needed because life expectancy is related to the successful treatment of CKD patients [14].

The family support studied focuses on family support for fluid restriction because [15] states that fluid management is one of the benchmarks for hemodialysis's success. This study proves that the rapid fluid output, and the increase in extracellular volume and the high increase in body weight in two phases of dialysis (IDWG) are risk factors for morbidity and mortality rates in CKD patients undergoing hemodialysis therapy. The success of hemodialysis action is based on 2 pillars, namely limiting fluids and removing metabolic waste products from the blood using a dialysis machine regulates the volume and osmolarity of extracellular fluid. So the questionnaire on family support for fluid restriction was used to examine the role of family in the fluid restriction in CKD patients undergoing HD therapy.

Research conducted by [16] In Chronic Kidney Disease patients who undergo hemodialysis, it is also shown that most of them do not comply with the restriction of fluids given, so that family support is urgently needed in fluid restriction. Refers to the theory of family support according to [17] that support provides the information, service support, instrumental support, and support needed to improve patient self-efficacy. Self-Efficacy and Social Support for Hemodialysis Patients in Improving Compliance with Fluid Restrictions in HD patients[8]. Researchers see that family support is needed to increase patient confidence in undergoing a series of therapy.

According to [10], self-efficacy is a person's belief in organizing and carrying out a series of actions needed to produce the desired results. In this study, the patient's selfconfidence focused on the belief in limiting fluid intake or, more precisely, to prevent excess or hypervolemic fluid build-up. The questionnaire on self-confidence in fluid restriction was made by researchers to see how confident patients were in doing fluid restriction. The self-confidence studied contains how HD patients can prescribed diet. The two variables studied and associated with the person test showed that the variable family support and the selfefficacy variable had a strong and positive pattern, meaning that the increasing family support, the increasing selfefficacy of the respondents.

Providing social support and other psychosocial factors can reduce the high risk of death and reduce dependence on medical care. Lack of social support will decrease the quality of life of CKD patients undergoing hemodialysis therapy [18]. Research by [19] on 50 elderly hemodialysis patients. The results showed that there was a significant relationship between family support and the anxiety level of elderly hemodialysis patients $(\mathrm{P}=0.026)$. The absence of family support affects the level of anxiety from mild to moderate. Patients without family support were 4.4 times more likely to experience mild to moderate anxiety than those who received family support. This study concluded that patients with chronic renal failure who are undergoing hemodialysis therapy who receive family support would also improve their quality of life. 
Forms of family support that focus on fluid restriction have a strong relationship with patients' confidence in doing fluid restriction that is expected not only for confidence but also on other variables that support the success of the HD therapy program.

\section{CONCLUSION}

There is an effect of family support on self-efficacy in CKD patients undergoing HD therapy with a $\mathrm{p}$ value of 0.000 . These results indicate that the need for family support to increase self-efficacy and the success of HD therapy for patients is family attitudes towards HD therapy by showing it through family interactions and reactions to family members. More extensive research is needed on forms of family support which include instrumental support, informational support, emotional support, hope support, and self-esteem support. It is also necessary to conduct research on self-efficacy with other dimensions, self-confidence and optimism, objective, responsible, rational, and realistic dimensions.

\section{CONFLICTS OF INTEREST}

The authors declare they have no conflicts of interest

\section{AUTHORS' CONTRIBUTIONS}

The author contributes directly to the implementation of the research. The involvement of the authors includes the proposal-making process and the research process. The research process includes the licensing process and research ethics management. After the research process is complete, it continues by preparing research reports and preparing research articles.

\section{ACKNOWLEDGMENTS}

The author would like to thank Universitas Muhammadiyah Purwokerto, who has provided full funding for research costs, the hospital with research permission, and the nurses in the HD room. Thanks a lot to all patients who are willing to become respondents in this study.

\section{REFERENCES}

[1] J.-C. Lv and L.-X. Zhang, "Prevalence and disease burden of chronic kidney disease," in Renal Fibrosis: Mechanisms and Therapies, Springer, 2019, pp. 3-15.

[2] K. Kaveh and P. L. Kimmel, "Compliance in hemodialysis patients: multidimensional measures in search of a gold standard.," Am. J. kidney Dis. Off. J. Natl. Kidney Found., vol. 37, no. 2, p. 244, 2001

[3] B. Fultz, "Critical Care Medicine: Principle of Diagnosis and Management in the Adult," Can. J. Anesth. Can. d'anesthésie, vol. 66, no. 11, pp. 1423-1424, 2019.

[4] R. Jayarathna, M. Munasinghe, W. Amarasinghe, Y. Gunathilaka, K. I. D. Fernando, and W. N. Priyanthi, "Factors Related to Non-compliance of Treatment among Chronic Kidney Disease Patients," 2019.

[5] G. Chironda and B. Bhengu, "Contributing factors to nonadherence among chronic kidney disease (CKD) patients: a systematic review of literature," Med. Clin. Rev., vol. 2, no.
4, p. 29, 2016.

[6] G. Chironda and B. R. Bhengu, "Motivators of adherence to integrated management among patients with chronic kidney disease: A qualitative study," Nurs. Health Sci., vol. 21, no. 1, pp. 63-70, 2019.

[7] P. Wiwoot, T. Lorga, A. Sangjan, and K. Santhuankeaw, "ROLES OF FAMILY IN THE PREVENTION OF CHRONIC KIDNEY DISEASE AND STROKE AMONG FAMILY MEMBERS AT RISK OF DEVELOPING THE DISEASES," in ANPOR Annual Conference Proceedings, 2017, p. 519

[8] Y. R. Chae, S. H. Lee, Y. M. Jo, and H. Y. Kang, "Factors related to Family Support for Hemodialysis Patients: A Systematic Review and Meta-analysis," Korean J. Adult Nurs., vol. 31, no. 2, pp. 123-135, 2019.

[9] S. Lippke, "Self-efficacy theory," Encycl. Personal. Individ. Differ., pp. 4722-4727, 2020.

[10] A. Bandura, "Self-efficacy: toward a unifying theory of behavioral change.," Psychol. Rev., vol. 84, no. 2, p. 191, 1977.

[11] Y. Wu, L. Tang, G. Li, H. Zhang, Z. Jiang, and S. S. Sedeh, "Self-care management importance in kidney illness: a comprehensive and systematic literature review," Netw. Model. Anal. Heal. Informatics Bioinforma., vol. 9, no. 1, pp. 1-13, 2020.

[12] A. Okhli and R. Masoudi, "The Impact of Family-Based Empowerment Pattern on Hemodialysis Patients in Golestan Province in 1394," Iran. J. Rehabil. Res. Nurs., vol. 5, no. 3, 2019.

[13] A. J. Christensen, T. W. Smith, C. W. Turner, J. M. Holman, M. C. Gregory, and M. A. Rich, "Family support, physical impairment, and adherence in hemodialysis: An investigation of main and buffering effects," J. Behav. Med., vol. 15, no. 4, pp. 313-325, 1992.

[14] J. E. Flythe, M. M. Assimon, and R. A. Overman, "Target weight achievement and ultrafiltration rate thresholds: potential patient implications," BMC Nephrol., vol. 18, no. 1, pp. 1-13, 2017.

[15] M. Hecking et al., "Greater fluid overload and lower interdialytic weight gain are independently associated with mortality in a large international hemodialysis population," Nephrol. Dial. Transplant., vol. 33, no. 10, pp. 1832-1842, 2018.

[16] N. L. G. I. Saraswati, N. L. Y. S. Antari, and N. L. G. Suwartini, "Hubungan Dukungan Keluarga Dengan Kepatuhan Pembatasan Cairan Pada Pasien Chronic Kidney Disease Yang Menjalani Hemodialisa," J. Ilmu Kesehat. Bhakti Husada Heal. Sci. J., vol. 10, no. 1, pp. 45-53, 2019.

[17] R. M. Friedman, "Restructuring of systems to emphasize prevention and family support.," J. Clin. Child Psychol., 1994.

[18] A. Untas et al., "The associations of social support and other psychosocial factors with mortality and quality of life in the dialysis outcomes and practice patterns study," Clin. J. Am. Soc. Nephrol., vol. 6, no. 1, pp. 142-152, 2011.

[19] A. Nugraha, G. U. Rahmah, and P. Budhiaji, "Effect of Family Support Towards Elderly Hemodialysis Patients' Anxiety Lev-el," Basic Appl. Nurs. Res. J., vol. 1, no. 1, pp. 20-24, 2020. 